\title{
Incubadora de aprendizagem na enfermagem: inovação no ensino do cuidado
}

\author{
Incubate of learning in nursing: an innovation in teaching the care
}

Incubadora de aprendizaje en la enfermería: innovación en la enseñanza del cuidado

\section{Diana Cecagno', Hedi Crecencia Heckler de SiQueira', Adriane Calvetti', Queli Lisiane Castro', AlacoQue Lorenzini Erdmann" \\ 'Universidade Federal de Pelotas. Grupo de Estudo e Pesquisa Gerenciamento Ecossistêmico em Enfermagem. Pelotas, RS "Universidade Federal de Santa Catarina, Departamento de Enfermagem, Florianópolis, SC}

\section{RESUMO}

Este estudo teve como objetivo discorrer sobre a incubadora de aprendizagem na enfermagem: inovação no ensino do cuidado. A incubadora pode ser considerada uma estratégia destinada a criar condições para a incubação, o desenvolvimento de idéias inovadoras e o despertar de novas idéias empreendedoras para o crescimento de pessoas, negócios e instituições. Ao utilizar o pensamento crítico, reflexivo associado ao fazer em enfermagem, em ambiente propício, a incubadora aponta para a inovação metodológica no ensino do cuidado.

Descritores: Enfermagem; Difusão de inovação; Aprendizagem.

\begin{abstract}
This study had as objective to reflect about incubate of learning in the nursing as an innovation in the teaching of the care. The incubate can be considered a strategy to create conditions for the incubation, the development of innovative ideas and the wakening of new enterprising ideas for the growth up of people, businesses and institutions. When using the critical, reflective thought associated when making in nursing, propitious environment, the incubate points with respect to methodological innovation at learning of the care.
\end{abstract}

Descriptors: Nursing; Diffusion of innovation; Learning.

\section{RESUMEN}

Este estudio tuvo como objetivo reflexionar sobre la incubadora de aprendizaje en la enfermería: innovación en la enseñanza del cuidado. La incubadora puede ser considerada una estrategia destinada a crear condiciones para la incubación, el desarrollo de ideas innovadoras y el despertar de nuevas ideas emprendedoras para el crecimiento de personas, negocios e instituciones. Al utilizar el pensamiento crítico, reflexivo asociado al hacer en enfermería, en ambiente propicio, la incubadora apunta para la innovación metodológica en la enseñanza del cuidado.

Descriptors: Enfermería; Disfusión de innovación; Aprendizaje. 


\section{INTRODUÇÃO}

A literatura pesquisada para esta reflexão aponta vários trabalhos ${ }^{(1-3)}$, realizados na última década, Que abordam a utilização de tecnologias no ensino de enfermagem. Essas tecnologias se encontram, na maioria das vezes, relacionadas com a área da administração/gerenciamento e apresentam uma aproximação significativa entre estas áreas de trabalho. Entretanto, a utilização da incubadora de aprendizagem como estratégia para o ensino do cuidado parece ser ainda algo novo. Esta estratégia ressalta a importância do diálogo criativo com o outro, a sensibilidade e a interação do ser humano com o ambiente, realizando o intercâmbio de idéias, experiências e a partir da prática criando novas tecnologias do cuidado construindo desta forma, novas maneiras de cuidar.

A enfermagem, como profissão, entendida como ação de cuidar, utiliza a aprendizagem como uma ferramenta indispensável para a capacitação e Qualificação profissional, resultando numa melhor forma de cuidar. Neste sentido "a atividade de cuidar surge da criatividade humana, das sensibilidades frente às trocas com o outro e das condições naturais de capacidade do ser humano de criar novas situações"(3) ou seja, as inovações/mudanças a serem instituídas no cuidado são criações emergidas da complexidade das relações do indivíduo com o coletivo e com o ambiente no Qual se insere.

A incubadora é uma nova forma de aprendizagem na enfermagem/saúde Que permite integrar a inovação, a tecnologia e a educação, possibilitando aos trabalhadores da área captar a realidade do cotidiano, despertar e aplicar novas idéias, aumentar competências e habilidades, adQuirir e adicionar conhecimento e, desta maneira, fazer diferença na sua trajetória profissional.

A Incubadora de Aprendizagem, vista nesta perspectiva, representa um novo modo de aprender, isto é, uma aprendizagem integrada com a mudança/inovação, buscando criar e agregar tecnologias à prática do cuidado no e com o ambiente de trabalho ${ }^{(1)}$. Esta estratégia já mencionada na Dissertação de Mestrado(4) teve como proposta trabalhar com o tema processo de aprendizagem no ambiente de trabalho. A pesquisa permitiu apontar caminhos capazes de proporcionar conscientização nos diferentes aspectos Que envolvem a construção do conhecimento e, em especial, propor mudanças de comportamento frente à realidade cotidiana, olhando o processo de aprendizagem de forma dinâmica, inovadora e criativa, em consonância e apoiadas às novas tecnologias da informação.

$\mathrm{Na}$ ótica da complexidade do ser humano e do mundo do trabalho da enfermagem, a construção do conhecimento no próprio ambiente de trabalho possibilita tanto a mudança e a renovação dos serviços, como a otimização da Qualidade do cuidado prestado. Cabe salientar Que Quanto mais se adiciona informação e conhecimento a um produto ou serviço, mais Qualidade ele terá, podendo até gerar novas informações e conhecimentos capazes de se reintegrar num dinâmico e contínuo processo de aprendizagem, expressando-se através da concretude do cuidado de enfermagem. Assim, tem-se como objetivo discorrer sobre a incubadora de aprendizagem na enfermagem: inovação no ensino do cuidado.

\section{INCUBADORA DE APRENDIZAGEM}

\section{Laboratório/Centro de Tecnologia - uma estratégia inovadora no ensino da enfermagem}

Incubadoras são descritas na literatura com diferentes definições, no entanto, assumem características, como mecanismos, destinadas a criar condições para o crescimento de instituições, negócios e pessoas. Elas oferecem serviços especializados, orientações, exigem espaço físico, infra-estrutura e pessoas Qualificadas capazes de assegurar o seu fortalecimento e a melhoria do desempenho de seus colaboradores ${ }^{(5)}$. Enquanto buscam criar condições para a implementação e desenvolvimento de novas idéias a serem construídas, testadas para serem colocadas em prática, funcionam como fomentadores de incubação desses conceitos e, de forma contínua, instigam a busca de novas idéias empreendedoras.

As incubadoras funcionam como verdadeiros centros/serviços/ empresas incubando e implantando projetos de aperfeiçoamento de atividades. Além disso, contribuem com o relacionamento interpessoal, a melhoria da Qualidade de ensino e aprendizagem e, principalmente, estimulam a criação de novos empreendimentos alicerçados nas necessidades do mercado. As incubadoras permitem desenvolver e testar novas idéias e com isso é possível aumentar o desenvolvimento do espírito empreendedor do grupo Que busca, através desta modalidade, ingressar e consolidar-se no mercado de trabalho, tornando-se multiplicador desse processo.

A literatura destaca Que a incubadora de aprendizagem é constituída por pessoas Que acreditam em mudanças no ambiente de aprendizagem, com estrutura e pessoal, para agir como um centro capaz de sustentar a teoria, ao mesmo tempo em Que conduz a um trabalho educacional prático, coerente e avançado ${ }^{(6)}$.

Diferentes campos de atuação já desenvolvem incubadoras tecnológicas, entre eles, a administração e a informática. Esses procuram criar, testar e lançar no mercado novos produtos e serviços inovadores otimizando empreendedores capazes de desenvolver, na prática, o Que aprenderam teoricamente. Esse conhecimento já produzido leva a conceituar a incubadora de aprendizagem na enfermagem como um laboratório/um centro de tecnologia no Qual se experiência práticas de cuidado, buscando estimular, criar, implementar e desenvolver novas idéias/novos empreendimentos, alicerçados nas necessidade do cliente, agregar inovação, traduzilas em produtos e/ou serviços, com a intenção de capacitar o profissional e, assim, aprimorar o cuidado de enfermagem. Por conseguinte, a incubadora de aprendizagem, sob essa ótica, consiste num novo espaço a ser conQuistado pela enfermagem, buscando estratégias para superar os desafios apresentados pela tecnologia, mesmo porQue, diante à dinâmica da realidade da ciência e da tecnologia, as informações se tornam obsoletas com a mesma rapidez Que são geradas.

As instituições de saúde podem transportar essas idéias com características semelhantes, utilizadas em diversas empresas, e proporcionar, através de um laboratório/um centro de tecnologia incubadora de aprendizagem, um novo modelo de aprendizagem para o desenvolvimento tecnológico de novos projetos empreendedores na enfermagem/saúde. Dessa forma, além da ampliação do conhecimento/aprendizado, poderá ser proporcionada uma melhoria da Qualidade de vida, ao ser humano trabalhador, no ambiente onde ele está inserido e, na enfermagem, das práticas do cuidado. Neste sentido, autores ${ }^{(7)}$ enfatizam Que as organizações de saúde constituem-se em ambientes complexos, e que a construção de novas e diferentes práticas de cuidado requer um novo e diferente olhar para as instituições de saúde e para o ambiente 
Que as cerca e com o Qual interage. Isso vem ao encontro da idéia de Que a aprendizagem necessita ser uma preocupação institucional, pois assim, se torna mais fácil conseguir os recursos humanos, financeiros e materiais necessários para promover, de forma contínua e sistemática, o aprendizado ${ }^{(8)}$. Esse fato se apóia na idéia de Que ao considerar Que a gerência/administração da instituição exerce tarefa indispensável à complementação de sua função, Que é a de mobilizar recursos materiais e humanos, para facilitar o acesso de profissionais à capacitação e Qualificação, incentivando a criatividade e responsabilidade. A incubadora tecnológica de aprendizagem pode servir de ponte entre as universidades, institutos de ensino e pesQuisa, instituições de trabalho e a sociedade, desenvolvendo um intenso intercâmbio entre elas, para capacitar, gerenciar e recriar uma tecnologia, a partir de conhecimentos básicos para sua compreensão ${ }^{(5)}$. Portanto, a incubadora de aprendizagem não se restringe somente aos clientes internos da enfermagem, mas oferece oportunidades mais amplas, permitindo o acesso a essa modalidade de ensino a outras instituições congêneres e/ou profissionais.

Considerando que a saúde é o produto obtido no coletivo e promovido através da interdisciplinaridade de serviços, dentre os Quais a área da enfermagem, esta necessita desenvolver o conhecimento para buscar, cada vez mais, avançar na melhoria do atendimento prestado ao cliente. O aprendizado coletivo deve ser a competência básica de uma instituição Que deseja coordenar diferentes serviços, integrar tecnologias, organizar o trabalho e agregar valor ao seu produto ${ }^{(9)}$.

Na enfermagem, adicionar valor ao produto/saúde pode ser visto como possibilidade de habilitar o profissional, tornando-o capaz de agregar os avanços tecnológicos ao conhecimento Que possui, permitir melhorias na organização do seu trabalho, convergindo para a melhor Qualidade do serviço, aumentando sua auto-estima, motivando-o a prosseguir no processo do "aprender a aprender".

Vários autores ${ }^{(5,6,10)}$ trabalham com as idéias de incubadoras tecnológicas ou de aprendizagem na área de administração, induzem para a possibilidade de desenvolvê-la em outras áreas, entre elas, a saúde.

Desta maneira, uma nova estratégia é apontada ${ }^{(1)}$ para ampliar as formas de cuidar na enfermagem associada às ações de aprendizagem. As autoras propõem a utilização da Incubadora de Aprendizagem na Enfermagem como uma inovação no ensino e aprendizagem do cuidado, capaz de propiciar a integração da tecnologia da informação ao cuidado, de desenvolver atitudes, competências e habilidades, relacioná-las com o mundo Que se impõe em termos de tecnologias cada vez mais avançadas e complexas, num ambiente organizacional Que por si só também é complexo.

\section{CONSIDERAÇÕES FINAIS}

O cotidiano de trabalho, sob a ótica tecnológica e social, integrase aos processos educativos, abrindo novas possibilidades de desenvolvimento individuais e coletivas voltadas para a aprendizagem. Assim, entende-se Que somente as atividades Que desafiam, Que instigam a refletir, (re)formular e (re)construir o fazer, motivam os trabalhadores e podem propiciar experiências significativas, ricas e contextualizadas, envolvendo-os em muitas atividades práticas e de aprendizagem ao longo da vida profissional.

Esse contexto desafiador condiz com o propósito de discorrer sobre a incubadora de aprendizagem na enfermagem, porQue se propõe uma inovação no ensino do cuidado. Busca-se, através da incubadora de aprendizagem na enfermagem, criar e implementar novos projetos e metodologias inovadoras de ensino, interconectados às novas tecnologias, a fim de utilizá-los como instrumentos/recursos para a aQuisição de saberes, habilidades e competências à prática gerencial, investigativa, assistencial e educacional.

É de fundamental importância Que os profissionais de enfermagem (re)conheçam as possibilidades e os recursos tecnológicos implementados à incubadora de aprendizagem, a fim de utilizá-la como estratégia de formação, Qualificação e atualização no processo de aprendizagem. Esse recurso facilita acompanhar as transformações constantes e inevitáveis Que norteiam a inserção do ser humano na organização da sociedade e na estrutura do trabalho, porQue o próprio perfil profissional sofre modificações e precisa ser adequadamente redimensionado, constantemente, em relação às inovações. Hoje, é necessário Questionar os paradigmas e estar habilitado a lidar com as mudanças na forma de produzir, armazenar e transmitir o conhecimento Que dão origem a novas formas de fazer, pensar e aprender. No entanto, isso não significa Que os enfermeiros devam se tornar especialistas nesta forma de aprendizagem, mas, é necessário conhecer as potencialidades dos instrumentos e saber utilizá-los ou indicá-los para avançar ou melhor Qualificar a prática profissional.

Ressalta-se Que as Instituições Que apóiam/incentivam, financiam, programam e desenvolvem uma incubadora de aprendizagem, encontram-se em destaque no mercado de trabalho porque é com base nas suas necessidades Que ela procura implementar os novos projetos. Inúmeras são as vantagens advindas da implementação de incubadoras de aprendizagem, tanto para a empresa, para os profissionais e clientes, fundamentada especificamente, na busca da tecnologia aliada a Qualidade do atendimento. Entretanto, diversas são as idéias Que podem ser utilizadas em defesa da utilização da Incubadora de Aprendizagem na enfermagem como estratégia de inovação no ensino do cuidado.

\section{REFERÊNCIAS}

1. Cecagno D, Siqueira HCH. Educação Continuada: um novo modelo de ensino na enfermagem - incubadora de aprendizagem. Pelotas: Ed Universitária PREC/UFPEL; 2006.

2. Erdmann AL. Sistemas de Cuidados de Enfermagem. Pelotas(RS): editora Universitária/UFPEL; 1996.

3. Souza AIJ, Erdmann AL. Contribuições para o Conhecimento em enfermagem à luz da Fenomenologia da percepção de Merleau-Ponty. Rev Gaúcha de Enferm 2006; 27(2): 166-75.
4. Cecagno D, Serviço de Educação Continuada na Enfermagem nas instituições de saúde do Município do Rio Grande [dissertação]. Rio Grande (RS): Fundação Universidade do Rio Grande; 2003.

5. Allemand R. Tecnologia da incubadora empresarial. Sapucaia do Sul; 2004. [citado em: 15 jan 2004]. Disponível em: http:/ /www.cefetrs.edu.br 
6. Karaaslanian I, Centros de aprendizagem. [citado em $27 \mathrm{dez}$ 2003]. Disponível em: http://learning.media.mit.edu.

7. Erdmann AL, Mello A, Meirelles BHS, Marino SRA. As organizações de Saúde na Perspectiva da Complexidade dos Sistemas de cuidado. Rev Bras Enferm 2004; 57(4): 467-7I.

8. Senge A. A Quinta disciplina: arte e prática da organização Que aprende. São Paulo: Best Seller; 2002.
9. Nadler DA, Gerstein MS, Shaw R. ArQuitetura organizacional: a chave para a mudança empresarial. Rio de Janeiro: Campus; 1993.

10. Terra B. A transferência de tecnologia em universidades empreendedoras: um caminho para a inovação tecnológica. Rio de Janeiro: Qualitymark; 200I. 